\title{
Eating behaviour, food preferences and dietary intake in relation to obesity and body-weight status
}

\author{
BY DAVID J. MELA \\ Consumer Sciences Department, Institute of Food Research, Earley Gate, \\ Whiteknights Road, Reading RG6 $6 \mathrm{BZ}$
}

Identification of behaviours which can be causally linked to overeating arguably presents insight into the aetiology of obesity and, perhaps, opportunities for specific interventions. This view underpins an extensive body of nutritional and behavioural literature directed at characterizing various aspects of eating behaviours in relation to present or past bodyweight status. The topics explored in this type of research have ranged broadly, from the microstructure of eating, through sensory and external cue responsiveness, to measures of actual food choice and intake. The present paper will attempt to briefly review some of these major areas of research, and then to integrate information coming from behavioural studies with current ideas in nutrition and metabolism. While the critical role of energy expenditure and the contributions of animal experimentation are acknowledged, the discussion will be restricted by focusing almost exclusively on studies of human eating behaviour and dietary intake.

\section{PROBLEMS OF MEASUREMENT}

It should be stated at the outset that there are major obstacles to identifying eating behaviours, food preferences and dietary habits which may be unequivocally implicated in the aetiology or maintenance of overweight or obesity. First, these conditions may result from very small aberrations in energy balance compounded over many years, such that the true behavioural or physiological phenomena of interest may be overwhelmed by errors in experimental measurement. Second, while marked effects may be observed in short-term behaviours in experimental situations, these may explain little of the variance in eating behaviour occurring under more realistic conditions. Third, most studies have examined subjects already overweight or obese; thus, observed behaviours could be an outcome of current status, and dissimilar to those preceding or coincident with periods of active weight gain. Fourth, much of the research in these areas is necessarily dependent on self-report measures known to be prone to substantial and non-random mis-reporting, or test procedures susceptible to cognitive bias. Last, use of indirect measures of body composition in some studies may generate classification errors, blurring potentially important distinctions between body size and body fatness. These caveats should be borne in mind throughout all the discussion which follows.

\section{EATING BEHAVIOUR: EXTERNALITY, RESTRAINT, MICROSTRUCTURE AND PATTERNS OF EATING}

\section{Externality}

In the late 1960s, Schachter and colleagues (Schachter, 1971; Schachter \& Rodin, 1974) initiated a series of studies which led to the so-called 'externality theory' of obesity. 
Compared with their lean counterparts, both obese rats and human subjects were argued to be more reactive to external cues (time, presence of food, situational effects, etc.) and less sensitive to internal hunger and satiety signals than their lean counterparts. According to this view, high external responsiveness would, given an environment of an easily accessible, abundant and highly palatable food supply, encourage overeating and, hence, the development of obesity.

These ideas became widely accepted and generated a large volume of related research in the 1970s. Many of the subsequent studies confirmed the original notion of externality; however, many did not, and this view lost favour as it became clear that the relationship between externality and overweight is much more complex than originally proposed (for reviews, see Leon \& Roth, 1977; Rodin, 1981; Spitzer \& Rodin, 1981). Nevertheless, this spawned a number of ideas which have continued to be the focus of research through to the present. In particular, in their comprehensive review of studies on human eating behaviour, Spitzer \& Rodin (1981) concluded that 'palatability is the most consistent variable influencing amount eaten and producing overweight-normal differences in amount eaten'. Specifically, in experimental studies, better-liked foods are not only consumed in higher quantities than lesser-liked foods, but the magnitude of this palatability effect is reliably found to be exaggerated in obese subjects. However, the relationships amongst sensory acceptance, actual food choices and intake, and the development and maintenance of obesity have never been fully explored in human research. Furthermore, provocative studies on weight change in children (Rodin \& Slochower, 1976) and responsiveness of infants (Milstein, 1980) suggest that externality may be an antecedent, and not simply a consequence or correlate of the tendency toward overeating and obesity. Thus, the possibility that certain traits of externality contribute to a predisposition to obesity remains a plausible hypothesis.

\section{Restraint}

Nisbett (1972) suggested that the obese-normal differences in eating behaviour identified by Schachter (1971) could be due to greater hunger experienced by obese individuals. This might be due to actual dieting or, as Nisbett (1972) originally proposed, many overweight individuals may be engaged in a chronic struggle to restrain their eating against a biological drive toward further weight gain. Dieting and restrained eating are prevalent amongst individuals whose weight is normal or below normal, and these ideas therefore prompted examination of the eating behaviour of subjects classified according to their degree of dietary restraint and dieting, rather than body weight alone.

The role of restrained eating in eating behaviour was initially explored in a series of studies by Herman and colleagues (Herman \& Mack, 1975; Herman, 1978; Herman et al. 1978) and made use of their Restraint Scale, assessing concern with dieting and weight, and short-term weight fluctuation. One of the crucial but initially surprising behavioural correlates of restraint is a tendency to exhibit 'disinhibited' eating. In the original observation by Herman \& Mack (1975), subjects were given preloads of zero, one or two glasses of a milkshake, and then asked to consume ice-cream ad libitum as part of a 'taste' test. While actual intake of ice-cream was, as expected, inversely related to the size of the preloads in subjects scoring low on the Restraint Scale, the ice-cream consumption of restrained subjects paradoxically increased with a greater preload. Subsequent studies showed that restrained subjects tended to eat more after a preload identified as high in 
energy, compared with the same preload identified as low in energy (Polivy, 1976). This counter-regulatory behaviour apparently occurs when the perceived intake of energy is sufficient to cause normally restrained eaters to suspend their self-imposed restraint, thereby releasing an underlying desire to eat (Herman \& Mack, 1975; Herman, 1978; Herman \& Polivy, 1984). The pattern of thinking identified with such behaviour has been characterized as, 'I've blown it already, so I might as well eat' (Polivy, 1976; Wardle, 1987). Many factors other than food preloads have been shown to precipitate overeating in restrained eaters, such as emotional events (including anxiety), the presence of other people overeating, the sight and smell of well-liked foods, and even the anticipation of a forthcoming high food intake (Herman \& Polivy, 1975; Herman, 1978; Polivy et al. 1979; Baucom \& Aiken, 1981; Ruderman et al. 1985; Rogers \& Hill, 1989). These findings have confirmed a major influence of cognition on short-term food intake, and suggest potential causal links between restraint and compulsive eating (Wardle, 1987), and perhaps longerterm failure of weight control.

The Restraint Scale of Herman et al. (1978) and more recent eating-behaviour questionnaires (Stunkard \& Messick, 1985; Van Strein et al. 1986b) have been used extensively in behavioural research over the last decade. The psychometrics and measurement of restraint, weight concern and dieting, and of tendencies for external, emotional, and disinhibited eating, and their associations with measures of body-weight status and physiological and behavioural traits have been the subject of considerable thought and research (for example, Herman, 1978; Van Strein et al. 1986a, 1995; Heatherton et al. 1988; Weber et al. 1988; Laessle et al. 1989a,b; Ho et al. 1990; Ogden \& Wardle, 1990; Tuschl et al. 1990; Westerterp-Platenga et al. 1991, 1992; Lowe, 1993; Ogden, 1993; Frye et al. 1994; DeCastro, 1995; Kanarek et al. 1995; Lawson et al. 1995). The interested reader is directed to this literature, as a full discussion of these issues is beyond the scope of the present review.

In relation to the development or maintenance of obesity, the role of restrained eating and related behaviours, especially tendency for disinhibited eating, remains suggestive, although unproven. Recent work has continued to refine these concepts and investigate the implications of maintaining dietary restraint in a culture and environment where energydense foods and opportunities to eat are ubiquitous, while slimness is promoted as the ideal of beauty, self-control and success. One interpretation of restraint research is that palatable, energy-dense foods may not be of concern solely because of their inherent nutritional composition, but that for many individuals consumption (or even the presence) of such foods may present a particularly potent stimulus for the breakdown of restraint, loss of dietary control, and overeating of these or other foods.

\section{Microstructure of eating}

Studies of the microstructure of eating have concentrated on specific measures of behaviour occurring within a single meal sitting, for example rate and dynamics of ingestion, bite size and chewing characteristics. There have been many attempts to use these variables and others to characterize the existence of an 'obese eating style' (see Spitzer \& Rodin, 1981; Rodin et al. 1989). Although characteristic individual patterns may be identified, it has proved difficult to show that they are consistently related to obesity per se, and virtually impossible to distinguish cause and effect. 
In experimental situations, better-liked meals or foods generate larger, longer meals, with an accelerated rate of eating (Hill \& McCutcheon, 1975, 1984; Bellisle \& Le Magnen, 1981; Bellisle et al. 1984; Westerterp-Platenga et al. 1991). Hill \& McCutcheon (1975) suggested that a more rapid eating style could be associated with the development of obesity because food intake might be occurring at a rate which outpaces the normal development of satiety and inhibition of eating. However, behaviour in such situations may clearly be dominated by, or interact with, underlying factors such as state of hunger, eating restraint and responsiveness to palatability. Furthermore, there may be an artifactual effect of body size, which is also associated with faster eating (Hill \& McCutcheon, 1984; Barkeling et al. 1995). Other studies have reported conflicting results in relation to the existence of differences in eating rates between obese and non-obese subjects (see Rodin et al. 1989; Westerterp-Platenga et al. 1991). In more sophisticated analyses of eating rates, Westerterp-Platenga et al. (1991, 1992) reported that both high restraint and obesity were associated with linear cumulative intakes (a lack of slowing) over an extended meal, while normal-weight, low-restraint subjects tended to decelerate their eating during the same period. However, measures of ingestion rates were not found to relate to measures of total intake and, in general, significant or consistent implications of the microstructure of eating for satiety mechanisms and overall control of intake have not been clearly demonstrated.

\section{Patterns of eating}

Interest in 'meal patterns' was largely stimulated by a combination of animal research and epidemiological studies in the early 1960s, which suggested that consumption of larger, less-frequent 'meals' was associated with a greater fat deposition and risk of obesity compared with a more-frequent pattern of eating (Fábry \& Tepperman, 1970; Leveille, 1970). This topic has been the subject of a recent comprehensive review (Burley et al. 1994), and will only be briefly summarized here. It should be noted that this general area of research is plagued by problems with definition of eating occasions and lack of data on eating frequency per se. Non-standardized colloquial terms such as 'meals' and 'snacks' are common even in the scientific literature, but are often poorly quantified, and conflate aspects of timing, frequency, amount and type of food consumed. Furthermore, overweight or dieting subjects may choose to alter eating frequency as part of their personal strategy for restraining intake in the hope of achieving weight reduction, or may have different criteria for what constitutes a 'meal'. This would point to reduced eating frequency as a result of overweight or obesity, rather than a cause (Kant et al. 1995b), as inferred from some epidemiological analyses, and suggests that additional behavioural characterization of subject populations would aid the interpretation of such data. It is also likely that individuals with higher levels of physical activity eat more frequently (e.g. Durrant et al. 1982; Butterworth et al. 1994), and this could generate results suggesting higher energy intakes (but lower fatness) in association with more frequent eating.

Although a number of epidemiological studies have supported an inverse relationship between measures of eating frequency and body-weight status (Fábry \& Tepperman, 1970; Ries, 1973; Kaufman et al. 1975; Metzner et al. 1977; Kulesza, 1982; Kant et al. 1995b), many recent investigations have not found this relationship (Morgan et al. 1983; Dreon et al. 1988; Summerbell, 1989; Edelstein et al. 1992; Basdevant et al. 1993; Ruxton et al. 1994; Anderson et al. 1995). However, limitations in the methods used to quantify eating 
patterns makes it difficult to draw definitive conclusions from these data. Some epidemiological investigations of the circadian distribution of energy intake have suggested that the obese consume a greater proportion of energy intake in the latter half of the day compared with lean individuals (Beaudoin \& Mayer, 1953; Baeke et al. 1983; Bellisle et al. 1988; Fricker et al. 1990), but other studies have failed to find such a relationship (Maxfield \& Konishi, 1966; Durrant et al. 1982; Anderson et al. 1995; Kant et al. 1995a). Overall, evidence for a causal link between the circadian distribution of energy intake and obesity is weak, when diet composition is taken into account.

Most laboratory studies placing subjects on fixed regimens of varied meal size and frequency have been of too short a duration to generate any data regarding effects on energy intake and fat deposition. Although Fábry et al. (1966) reported greater fat deposition amongst adolescents eating three meals daily ( $v$. five or seven) over 1 year, other prospective studies which have investigated the impact of eating meal frequency on normal energy balance have generally found little effect (Dallosso et al. 1982; Verboeket-van de Venne et al. 1993). Some investigators have suggested that high eating frequency in the form of 'snacking' is common in the obese (Björvell et al. 1985; Basdevant et al. 1993), and possibly causally related to obesity (Booth, 1988); however, empirical support for this is lacking. The likelihood of certain eating patterns predisposing to excessive energy intakes may be resolved with better understanding of the regulation of meal-to-meal energy intake. In particular, there is a need for experimental work to determine the effects of changes in eating frequency, and particularly the timing of insertion of extra eating events ('snacks'), and their composition, on long-term energy balance.

\section{SENSORY RESPONSES AND FOOD PREFERENCES IN OBESITY}

\section{Food preferences}

There are few published studies comparing either the expressed food preferences or the actual food or food groups (as opposed to nutrients) consumed by lean and obese individuals. A major problem encountered in such approaches is that food categories are usually defined by investigators, based on subjective similarities in nutrient profile (highfat, low-energy-density, etc.), sensory characteristics (e.g. sweet, savoury), source or site of preparation (processed $v$. home-prepared), role in cuisine ('snacks' $v$. 'meals'), etc., or various combinations of these. These many different categorization schemes are clearly incompatible with each other, and specific schemes often seem contrived and illogical. Causality is clearly difficult to establish, since obese individuals may select, or claim to select or avoid certain foods as a result of their present weight status.

Dietary intake studies have generally revealed few, if any, consistent differences in specific food selection patterns associated with obesity (e.g. Kulesza, 1982; Baeke et al. 1983; Morgan et al. 1983; Pangborn et al. 1985). In one of the most sophisticated field studies, Coates et al. (1978) randomly selected and visited sixty-five suburban homes, collecting anthropometric data on family members and categorizing stored food by a defined system based on both energy density ( $\mathrm{kJ}$ per serving) and a set of overlapping descriptive categories. In general, they found little evidence of any consistent relationships between degree of family or parental overweight and presence of foods in particular categories. However, degree of overweight in fathers was positively correlated with the 
number of so-called 'junk' (high-fat/high-sugar, ready-to-eat) and dessert items, and negatively correlated with low-energy foods.

In a summary of their extensive studies of (US) armed forces personnel, Meiselman and colleagues (Meiselman, 1977; Meiselman \& Wyant, 1981) reported that overweight subjects assigned higher hedonic and preferred frequency ratings to entrées, particularly meats. However, the authors note that this may be confounded by a sex effect, with preferences of males and females tending to correspond to the respective preferences of overweight and average-weight subjects (Meiselman \& Wyant, 1981). This difference between sexes is echoed in the work of Drewnowski et al. (1992), who reported that while obese males indicated greater preferences for low-carbohydrate, high-fat or fat/protein foods (e.g. meats), obese females preferred more fat/carbohydrate combination and sweet items (e.g. cakes, ice-cream). However, the sex differences reported in that work are not consistently split along these lines, and the absence of corresponding responses from normal-weight individuals makes it unclear whether the expressed preferences are specific to obese subjects, or characterize the population as a whole.

\section{Sensory responses: general}

It is commonly suggested that the preference for selected sensory qualities may be heightened in obesity, and that this may be a contributing factor in excessive food intakes. Historically, much of this research has been directed toward sweet taste preferences, although most studies have found that obese and lean individuals do not differ in their general sensitivity to or perceptions of intensity of sweetness, or in their liking for sweetness in foods or beverages (see Grinker, 1978; Malcolm et al. 1980; Frijters \& Rasmussen-Conrad, 1982; Drewnowski et al. 1985). This also includes studies of newborn babies of obese and non-obese mothers (Grinker et al. 1986). However, there are occasional reports of both increased and decreased liking for sweet taste among overweight or obese individuals, and more complex assessment methods have pointed to possible effects of recent or long-term weight loss on sweet taste preferences (e.g. Rodin et al. 1976; Rodin, 1980; Kleifield \& Lowe, 1990).

Far less information is available regarding chemosensory qualities other than sweetness. No obese-lean differences have been reported for sensitivity to or liking for non-sweet tastes (Malcolm et al. 1980), or a food-related aroma (benzaldehyde; Thompson et al. 1977), although Witherly et al. (1980) noted possible differences in perception and liking for viscosity. Many of the early sensory studies are viewed as lacking ecological validity, because they have used methods or focused on stimuli (e.g. glucose in water) which are irrelevant or unrelated to real world perception of normal foods (Mela, 1992), and current work tends to be oriented toward more complex real or model foods.

\section{Sensory responses: fats}

Most recent work on sensory perception and preferences in relation to obesity has focused on fats. Obese and lean subjects have not been found to differ in their intensity ratings for fat content or creaminess of a range of sweetened milk and cream samples (Drewnowski et al. 1985) or model emulsions (Mela et al. 1994). However, Drewnowski and colleagues (Drewnowski \& Greenwood, 1983; Drewnowski et al. 1985), showed that fat could greatly 
enhance liking for a sweetened, milk-based test food, and raised the notion that sugar might represent an important vehicle for sensory acceptance of fat in the diet. They also reported that obese and recently reduced, formerly obese, individuals showed enhanced preferences for higher fat levels in this test food system, and suggested that liking and consumption of sweet, high-fat foods may be a particular feature in the development or maintenance of obesity (Drewnowski et al. 1985), although this notion lacks other support (see below). Subsequent studies by Drewnowski and colleagues (Drewnowski et al. 1991; Drewnowski \& Holden-Wiltse, 1992) have suggested that a greater preference for sweet, high-fat stimuli is particularly associated with a history of weight cycling.

The work of Drewnowski and colleagues (Drewnowski \& Greenwood, 1983; Drewnowski et al. 1985, 1991; Drewnowski \& Holden-Wiltse, 1992), has focused exclusively on fat-sugar combinations, and their results are, therefore, invariably interpreted as suggesting that these are of particular concern in relation to food preferences and control of eating. We (Mela \& Sacchetti, 1991) found a positive relationship, in subjects of normal weight-for-height, between percentage body fat and the preferred fat content for a test battery comprising both sweet and savoury foods, supporting the possibility that a more generalized fat or fat-savoury preference might be linked to a predisposition for obesity. This view is in agreement with earlier ideas relating to heightened responsiveness to palatability in general. It is also supported by the results of Kanarek et al. (1995), who found that liking for a higher fat content in a test food (popcorn) was increased by higher salt content amongst restrained, but not unrestrained, women, while measures of restraint did not relate to consistent differences in response to fat content of a sweet-fat combination (Frye et al. 1994). However, Warwick \& Schiffman (1990) reported no clear evidence for a greater fat preference amongst overweight subjects, for either fat-sugar or fat-salt mixtures, although these findings are weakened by the fact that the latter stimuli (salt added to milk or cream) were generally disliked. More recently, fisher \& Birch (1995) assessed fat preferences of young children using a test battery comprising savoury high-fat items and a mix of sweet and savoury low-fat items, and found significant positive correlations between fat preferences and measures of both child and parent fatness, and child's fat intake.

Based on dietary intake analyses, Emmett \& Heaton (1995) have recently proposed that added sugars act as a particularly important vehicle for fat, a feature of this view being that sweetness promotes greater fat intake 'by making the fat more palatable' (Emmett \& Heaton, 1995, p. 1537). However, in terms of the putative relationships amongst obesity, sensory preferences, and fat intakes, a dominant role for salted, savoury (rather than sugared, sweet) fat sources must be considered plausible, perhaps likely, based on the existing sensory and food preference research and population intake data. This view gains support from analyses of data from a study where we asked subjects to assign predominant taste characteristics to foods as eaten and recorded, which revealed that fat intakes correlated positively with measures of consumption of foods characterized as 'salty', but negatively with intakes of 'sweet' foods (unpublished analyses of data from Mela, 1989). Furthermore, the vast majority of dietary fat in the UK, like most Western nations, is contributed by meat and meat products, spreading fats, dairy products, and other foods which are low in carbohydrate and generally unsweetened (Gregory et al. 1990; Ministry of Agriculture, fisheries and Food, 1995). Last, epidemiological data support a link between fat intakes, but not sugar, and obesity (see p. 810). However, the relationships amongst 
sugar (and salt) and fat intakes, sensory preferences, and weight status, would be clarified by improved identification of the sources of variance in fat intakes, and by work linking actual food choices and individual consumer characteristics with subjective (sensory) and objective (nutrient composition) information on specific foods.

\section{OBESITY AND DIETARY INTAKE}

A wide range of evidence from human metabolic and feeding studies points to fat as the dietary constituent most likely to be causally implicated in excessive energy intake and weight gain (for reviews, see Ravussin \& Swinburn, 1992; Mela, 1995a, 1996; Prentice, 1995), although this may in part be mediated indirectly through effects on energy density (Poppitt, 1995). However, a predisposition to obesity appears to be associated with defects in the ability to raise fat oxidation commensurate with moderate or high fat intakes (see Astrup, 1993; Schutz, 1995). This also appears to be characteristic of formerly obese subjects (Astrup et al. 1994a; Larson et al. 1995) and, notably, non-obese restrained eaters (Verboeket-van de Venne et al. 1994). It has been proposed that obesity is an adaptive response to a high-fat diet, with the necessary equilibration of fat intake and oxidation being achieved through expansion of fat stores (Astrup et al. 1994b; Schutz, 1995), if not through increased physical activity (Tremblay \& Alméras, 1995).

The epidemiological studies of fat intake and obesity have recently been reviewed (Lissner \& Heitmann, 1995), and generally support a relationship in accord with the evidence from sensory and metabolic studies. Cross-sectional and, to a lesser extent, prospective studies indicate that high fat intakes are associated with greater relative weight. Recent longitudinal analyses by Heitmann et al. (1995) are furthermore compatible with the results of metabolic studies, indicating that high dietary fat intakes were associated with weight gains only in subjects predisposed to obesity. In contrast to results with fat, dietaryintake studies have frequently found measures of weight status negatively related to measures of intakes of sugars, specified as sucrose (Dreon et al. 1988), added sugars (Lewis et al. 1992; Bolton-Smith \& Woodward, 1994), or total sugars (Miller et al. 1990; Gibson, 1993; Bolton-Smith \& Woodward, 1994). These negative findings may partly occur as an artifact of the inverse relationship between sugar and fat intakes in most populations (Gibney, 1980; Lewis et al. 1992; Gibson, 1993; Baghurst et al. 1994), although there is extensive support for the view that carbohydrates are generally protective against weight gain and obesity (Astrup \& Raben, 1995).

\section{CONCLUSIONS: LINKING EATING BEHAVIOUR, PREFERENCES AND DIETARY INTAKE}

Fig. 1 is an attempt to integrate many of the behavioural and metabolic events described previously, and show their association with overeating and fat accretion. Present knowledge is consistent with the view that preferences for, and consumption of, dietary fat are linked to weight status. Consumption of diets moderate or high in fat or energy density (with low physical activity levels) appear to be critically implicated in the development of obesity amongst susceptible individuals. There may be additional confounding effects; for example, physical activity may be associated with lower fat intakes (Simoes et al. 1995), and possibly also to changes in sensory or food preferences. Regardless of specific diet and 


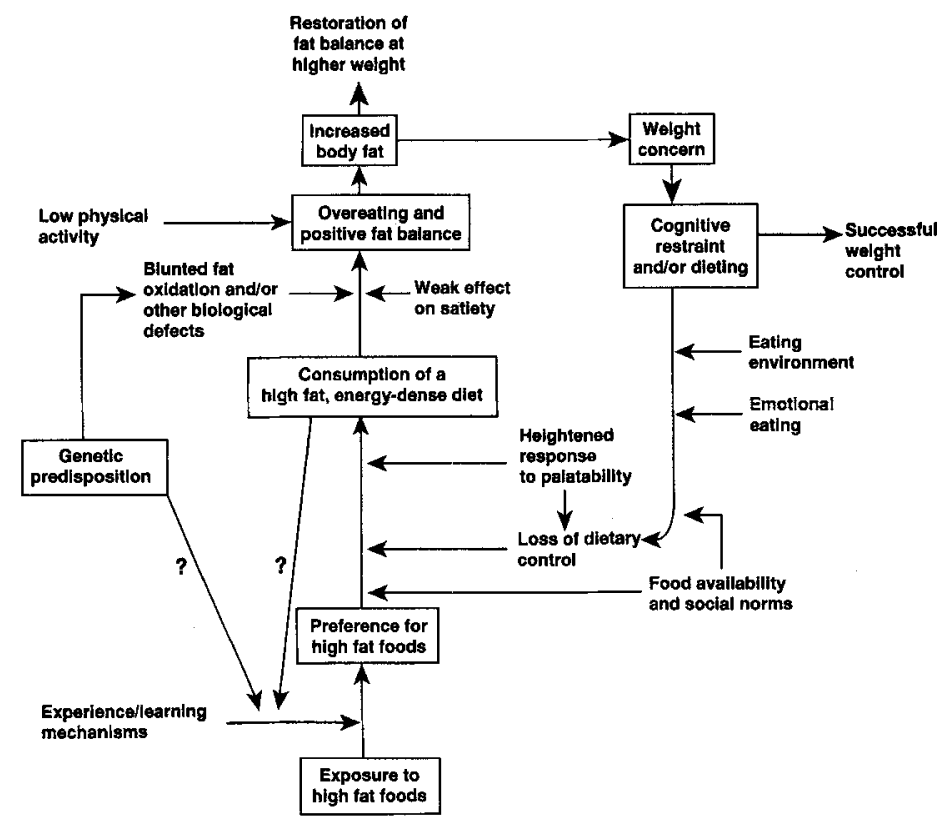

Fig. 1. Simple schematic linking prominent aspects of eating behaviour, food preferences and intake to the development of obesity. Starting point can be any boxed factor; not all factors are necessary or sufficient.

lifestyle, a positive fat balance appears to be the outcome of a causal chain which might start at several points, with a range of physiological and behavioural factors potentially contributing.

If phenotypic expression of a genetic predisposition toward obesity has consumption of a high fat intake as an important precursor, then the origins of this voluntary behaviour warrant consideration. 'Palatability' is commonly invoked as an explanation, although often with little consideration of the theoretical or empirical background to this issue. In fact, the fundamental cause of high fat preferences and intakes in obesity remains obscure. The basis for fat preferences in general has recently been reviewed (Mela, 1995b), and that analysis suggests that post-ingestive, psychobiological effects of fats may contribute to an associative conditioning process, through which a liking for fat-associated sensory qualities is acquired by experience.

The model in Fig. 1 allows for interplay of physiological and cognitive forces which might act to promote higher fat intakes in association with the susceptibility to, or presence of, obesity. Fat-containing foods might conceivably have greater reinforcing psychobiological effects for certain individuals or under certain conditions, therefore becoming more potent stimuli for the acquisition and maintenance of conditioned preferences, and increased liking. Physiologically, this might be mediated through variations in the stimulation or function of neural mechanisms involved in the acquisition or expression of hedonic responses in general. Could these in some way be ultimately linked to metabolic handling of fat? An appealing but completely speculative scenario would posit a single underlying mechanism, causing both a preference for a high fat intake as well as predisposing individuals to gain weight on such a diet. Empirically, it may be 
possible to test for links between characteristics of metabolism (e.g. measures of fat oxidation) and the existence or acquisition of preferences. By any mechanism, however, the physiological effects of energy-dense, high-fat foods, when combined with a heightened responsiveness to such foods specifically or to palatability generally, or given a tendency for disinhibited eating, creates ideal nutritional and psychological conditions for excessive intakes and poor weight control. Understanding of these food and behavioural characteristics and their links to overeating and obesity can potentially contribute to formulating and predicting responses to prevention and treatment strategies.

\section{REFERENCES}

Anderson, A. O., Gatenby, S. J., Walker, A. D., Mela, D. J. \& Southon, S. (1995). Dietary patterns in healthy adult volunteers: A preliminary investigation. In Proceedings of the Second International Conference on Dietary Assessment Methods, Abstr. no. 6. Boston: Harvard School of Public Health.

Astrup, A. (1993). Diet composition, substrate balances and body fat in subjects with a predisposition to obesity. International Journal of Obesity 17, Suppl. 3, S32-S36.

Astrup, A., Buemann, B., Christensen, N. J. \& Toubro, S. (1994a). Failure to increase lipid oxidation in response to increasing dietary fat content in formerly obese women. American Journal of Physiology 266, E592-E599.

Astrup, A., Buemann, B., Western, P., Toubro, S., Raben, A. \& Christensen, N. J. (1994b). Obesity as an adaptation to a high fat diet: Evidence from a cross-sectional study. American Journal of Clinical Nutrition 59, 350-355.

Astrup, A. \& Raben, A. (1995). Carbohydrate and obesity. International Journal of Obesity 19, Suppl. 5, S27-S37.

Baecke, J. A. H., Van Staveren, W. A. \& Burema, J. (1983). Food consumption, habitual physical activity and body fatness in young Dutch adults. American Journal of Clinical Nutrition 37, 278-286.

Baghurst, K. I., Baghurst, P. A. \& Record, S. J. (1994). Demographic and dietary profiles of high and low fat consumers in Australia. Journal of Epidemiology and Community Health 48, 26-32.

Barkeling, B., Rössner, S. \& Sjöberg, A. (1995). Methodological studies on single meal food intake characteristics in normal weight and obese men and women. International Journal of Obesity 19, 284-290.

Basdevant, A., Craplet, C. \& Guy-Grand, B. (1993). Snacking patterns in obese French women. Appetite 21, 17-23.

Baucom, D. H. \& Aiken, P. A. (1981). Effect of depressed mood on eating among obese and nonobese dieting and nondieting persons. Journal of Personality and Social Psychology 41, 577-585.

Beaudoin, R. \& Mayer, J. (1953). Food intake of obese and non-obese women. Journal of the American Dietetic Association 29, 29-33.

Bellisle, F. \& Le Magnen, J. (1981). The structure of meals in humans: eating and drinking patterns in lean and obese subjects. Physiology and Behavior 27, 649-658.

Bellisle, F., Lucas, F. \& Le Magnen, J. (1984). Deprivation, palatability and the microstructure of meals in human subjects. Appetite 5, 85-94.

Bellisle, F., Rolland-Cachera, M. F., Deheeger, M. \& Guilloud-Battaille, M. (1988). Obesity and food intake in children: Evidence for a role of metabolic and/or behavioral daily rhythms. Appetite 11, 111-118.

Björvell, H., Ronnberg, S. \& Rössner, S. (1985). Eating patterns described by a group of treatment seeking overweight women and normal weight women. Scandinavian Journal of Behavior Therapy 14, 147-156.

Bolton-Smith, C. \& Woodward, M. (1994). Dietary composition and fat to sugar ratios in relation to obesity. International Journal of Obesity 18, 820-828.

Booth, D. A. (1988). Mechanisms from models - actual effects from real life: the zero-calorie drink-break option. Appetite 11, Suppl., 94-102.

Burley, V. J., Gatenby, S. J., Anderson, A. O. \& Mela, D. J. (1994). Relationships Between Eating Frequency, Energy Intake and Body Weight Status: A Critical Review. London: The Biscuit, Cake, Chocolate and Confectionery Alliance.

Butterworth, D. E., Nieman, D. C., Butler, J. V. \& Herring, J. L. (1994). Food intake patterns of marathon runners. International Journal of Sport Nutrition 4, 1-7.

Coates, T. J., Jeffrey, R. W. \& Wing, R. R. (1978). The relationship between persons' relative body weights and the quality and quantity of food stored in their homes. Addictive Behaviors 3, 179-184. 
Dallosso, H. M., Murgatroyd, P. R. \& James, W. P. T. (1982). Feeding frequency and energy balance in adult males. Human Nutrition: Clinical Nutrition 36C, 25-39.

DeCastro, J. M. (1995). The relationship of cognitive restraint to the spontaneous food and fluid intake of freeliving humans. Physiology and Behavior 57, 287-295.

Dreon, D. M., Frey-Hewitt, B., Ellsworth, N., Williams, P. T., Terry, R. B. \& Wood, P. D. (1988). Dietary fat: carbohydrate ratio and obesity in middle-aged men. American Journal of Clinical Nutrition 47, 995-1000.

Drewnowski, A., Brunzell, J. D., Sande, K., Iverius, P. H. \& Greenwood, M. R. C: (1985). Sweet tooth reconsidered: Taste responsiveness in human obesity. Physiology and Behavior 35, 617-622.

Drewnowski, A. \& Greenwood, M. R. C. (1983). Cream and sugar: Human preferences for high-fat foods. Physiology and Behavior 30, 629-633.

Drewnowski, A. \& Holden-Wiltse, J. (1992). Taste responses and food preferences in obese women: Effects of weight cycling. International Journal of Obesity 16, 639-648.

Drewnowski, A., Kurth, C., Holden-Wiltse, J. \& Saari, J. (1992). Food preferences in human obesity: carbohydrate versus fats. Appetite 18, 207-221.

Drewnowski, A., Kurth, C. L. \& Rahaim, J. O. (1991). Taste preferences in human obesity: environmental and familial factors. American Journal of Clinical Nutrition 54, 635-641.

Durrant, M. L., Royston, P. \& Wloch, R. T. (1982). Effect of exercise on energy intake and eating patterns in lean and obese humans. Physiology and Behavior 29, 449-454.

Edelstein, S. L., Barrett-Connor, E. L., Wingard, D. L. \& Cohn, B. A. (1992). Increased meal frequency associated with decreased cholesterol concentrations; Rancho Bernardo, CA, 1984-1987. American Joumal of Clinical Nutrition 55, 664-669.

Emmett, P. M. \& Heaton, K. W. (1995). Is extrinsic sugar a vehicle for dietary fat? Lancet 345, 1537-1540.

Fábry, P., Hejda, S., Cerny, K., Osankova, K. \& Pechar, J. (1966). Effect of meal frequency in school children. Changes in the weight-height proportion and skin-fold thickness. American Journal of Clinical Nutrition 18, 358-361.

Fábry, P. \& Tepperman, J. (1970). Meal frequency - a possible factor in human pathology. American Journal of Clinical Nutrition 23, 1059-1068.

Fisher, J. O. \& Birch, L. L. (1995). Fat preference and fat consumption of 3- to 5-year-old children are related to parental adiposity. Journal of the American Dietetic Association 95, 759-764.

Fricker, J., Giroux, S., Fumeron, F. \& Apfelbaum, M. (1990). Circadian rhythm of energy intake and corpulence status in adults. International Journal of Obesity 14, 387-393.

Frijters, J. E. R. \& Rasmussen-Conrad, E. L. (1982). Sensory discrimination, intensity perception, and affective judgment of sucrose-sweetness in the overweight. Journal of General Psychology 107, 233-247.

Frye, C. A., Crystal, S., Ward, K. D. \& Kanarek, R. B. (1994). Menstrual cycle and dietary restraint influence taste preferences in young women. Physiology and Behavior 55, 561-567.

Gibney, M. J. (1980). Dietary guidelines: A critical appraisal. Journal of Human Nutrition and Dietetics 3, 245-254.

Gibson, S. A. (1993). Consumption and sources of sugar in the diets of British schoolchildren: Are high-sugar diets nutritionally inferior? Journal of Human Nutrition and Dietetics 6, 355-371.

Gregory, J., Foster, K., Tyler, H. \& Wiseman, M. (1990). The Dietary and Nutritional Survey of British Adults. London: H.M. Stationery Office.

Grinker, J. (1978). Obesity and sweet taste. American Journal of Clinical Nutrition 31, 1078-1087.

Grinker, J. A., Gropman-Rubin, J. \& Bose, K. (1986). Sweet preference and body fatness: Neonatal data. Nutrition and Behavior 3, 197-209.

Heatherton, T. F., Herman, C. P., Polivy, J., King, G. A. \& McGree, S. T. (1988). The (mis)measurement of restraint: An analysis of conceptual and psychometric issues. Journal of Abnormal Psychology 97, 19-28.

Heitmann, B. T., Lissner, L., Sørensen, T. I. A. \& Bengtsson, C. (1995). Dietary fat intake and weight gain in women genetically predisposed for obesity. American Journal of Clinical Nutrition 61, 1213-1217.

Herman, C. P. (1978). Restrained eating. Psychiatric Clinics of North America 1, 593-607.

Herman, C. P. \& Mack, D. (1975). Restrained and unrestrained eating. Journal of Personality 43, 647-660.

Herman, C. P. \& Polivy, J. (1975). Anxiety, restraint and eating behaviour. Journal of Abnormal Psychology 6, $666-672$.

Herman, C. P. \& Polivy, J. (1984). A boundary model for the regulation of eating. In Eating and Its Disorders, pp. 141-156 [A. J. Stunkard and E. Stellar, editors]. New York: Raven Press.

Herman, C. P., Polivy, J., Pliner, P., Threlkeld, J. \& Munic, D. (1978). Distractibility in dieters and nondieters: An alternative view of 'externality'. Journal of Personality and Social Psychology 36, 536-548. 
Hill, S. W. \& McCutcheon, N. B. (1975). Eating responses of obese and nonobese humans during dinner meals. Psychosomatic Medicine 37, 395-401.

Hill, S. W. \& McCutcheon, N. B. (1984). Contributions of obesity, gender, hunger, food preference, and body size to bite size, bite speed, and rate of eating. Appetite 5, 73-83.

Ho, E. E., Liszt, A. \& Pudel, V. (1990). The effect of energy content and sweet taste on food consumption in restrained and non-restrained eaters. Journal of the American Dietetic Association 90, 1223-1228.

Kanarek, R. B., Ryu, M. \& Przypek, J. (1995). Preferences for foods with varying levels of salt and fat differ as a function of dietary restraint and exercise but not menstrual cycle. Physiology and Behavior 57, 821-826.

Kant, A. K., Ballard-Barbash, R. \& Schatzkin, A. (1995a). Evening eating and its relation to self-reported body weight and nutrient intake in women, CSfiI 1985-86. Joumal of the American College of Nutrition 14, $358-363$.

Kant, A. K., Schatzkin, A., Graubard, B. I. \& Ballard-Barbash, R. (1995b). Frequency of eating occasions and weight change in the NHANES I Epidemiologic Follow-up Study. International Journal of Obesity 19, 468-474.

Kaufman, N. A,, Poznanski, R. \& Guggenheim, K. (1975). Eating habits and opinions of teen-agers on nutrition and obesity. Journal of the American Dietetic Association 66, 264-268.

Kleifield, E. I. \& Lowe, M. R. (1990). Weight loss and sweetness preferences: The effects of recent versus past weight loss. Physiology and Behavior 49, 1037-1042.

Kulesza, W. (1982). Dietary intake in obese women. Appetite 3, 61-68.

Laessle, R. G., Tuschl, R. J., Kotthaus, B. C. \& Pirke, K. M. (1989a). A comparison of the validity of three scales for the assessment of dietary restraint. Journal of Abnormal Psychology 98, 504-507.

Laessle, R. G., Tuschl, R. J., Kotthaus, B. C. \& Pirke, K. M. (1989b). Behavioral and biological correlates of dietary restraint in normal life. Appetite 12, 83-94.

Larson, D. E., Ferraro, R. T., Robertson, D. S. \& Ravussin, E. (1995). Energy metabolism in weight-stable postobese individuals. American Journal of Clinical Nutrition 62, 735-739.

Lawson, O. J., Williamson, D. A., Champagne, C. M., DeLany, J. P., Brooks, E. R., Howat, P. M., Wozniac, P. J., Bray, G. A. \& Ryan, D. H. (1995). The association of body weight, dietary intake, and energy expenditure with dietary restraint and disinhibition. Obesity Research 3, 153-161.

Leon, G. R. \& Roth, L. (1977). Obesity: Causes, correlations, and speculations. Psychological Bulletin 84, $117-139$.

Leveille, G. (1970). Adipose tissue metabolism. Influence of periodicity of eating and diet composition. Federation Proceedings 29, 1294-1301.

Lewis, C. J., Park, Y. K., Dexter, P. B. \& Yetley, E. A. (1992). Nutrient intakes and body weights of persons consuming high and moderate levels of sugars. Journal of the American Dietetic Association 92, 708-713.

Lissner, L. \& Heitmann, B. L. (1995). Dietary fat and obesity: Evidence from epidemiology. European Journal of Clinical Nutrition 49, 79-90.

Lowe, M. R. (1993). The effects of dieting on eating behavior: A three-factor model. Psychological Bulletin 114, $100-121$.

Malcolm, R., O’Neill, P. M., Hirsch, A. A., Currey, H. S. \& Moskowitz, G. (1980). Taste hedonics and thresholds in obesity. International Journal of Obesity 4, 203-212.

Maxfield, E. \& Konishi, F. (1966). Patterns of food intake and physical activity in obesity. Journal of the American Dietetic Association 49, 406-408.

Meiselman, H. L. (1977). The role of sweetness in the food preference of young adults. In Taste and Development. The Genesis of Sweet Taste Preference. DHEW Publication (NIH) 77-1068, pp. 269-279 [J. M. Weiffenbach, editor]. Washington, DC: US Government Printing Office.

Meiselman, H. L. \& Wyant, K. W. (1981). Food preferences and flavor experiences. In Criteria of Food Acceptance, pp. 144-152 [J. Solms and R. L. Hall, editors]. Zurich: Forster Verlag AG.

Mela, D. J. (1989). Gustatory function and dietary habits in users and non-users of smokeless tobacco. American Journal of Clinical Nutrition 49, 482-489.

Mela, D. J. (1992). Sensory evaluation methods in nutrition and dietetics research. In Research: Successful Approaches, pp. 220-247 [E. R. Monsen, editor]. Chicago: American Dietetic Association.

Mela, D. J. (1995a). Implications of fat replacement for nutrition and food intake. European Journal of Medical Research 1, 78-83.

Mela, D. J. (1995b). Understanding fat preference and consumption: Applications of behavioural sciences to a nutritional problem. Proceedings of the Nutrition Society 54, 453-464.

Mela, D. J. (1996). Assessing the dietary implications of macronutrient substitutes. In Progress in Obesity 
Research 7, pp. 423-430 [A. Angel, H. Anderson, C. Bouchard, D. Lau, L. Leiter and R. Mendelson, editors]. London: John Libbey \& Co.

Mela, D. J., Langley, K. \& Martin, A. (1994). Sensory assessment of fat content: Effect of emulsion and subject characteristics. Appetite 22, 67-81.

Mela, D. J. \& Sacchetti, D. S. (1991). Sensory preferences for fats in foods: relationships to diet and body composition. American Journal of Clinical Nutrition 53, 908-915.

Metzner, H. L., Lamphiear, D. E., Wheeler, N. C. \& Larkin, F. A. (1977). The relationship between frequency of eating and adiposity in adult men and women in the Tecumseh Community Health Study. American Journal of Clinical Nutrition 30, 712-715.

Miller, W. C., Linderman, A. K., Wallace, J. \& Niederpruem, M. (1990). Diet composition, energy intake, and exercise in relation to body fat in men and women. American Journal of Cinical Nutrition 52, 426-430.

Milstein, R. M. (1980). Responsiveness of newborn infants of overweight and normal weight parents. Appetite 1, 65-74.

Ministry of Agriculture, fisheries and Food (1995). National Food Survey 1994. Annual Report of Household Food Consumption and Expenditure. London: H.M. Stationery Office.

Morgan, K. J., Johnson, S. R. \& Stampley, G. L. (1983). Children's frequency of eating, total sugar intake and weight/height stature. Nutrition Research 3, 635-652.

Nisbett, R. E. (1972). Hunger, obesity, and the ventromedial hypothalamus. Psychology Reviews 79, $433-453$.

Ogden, J. (1993). The measurement of restraint. Confounding success and failure? International Journal of Eating Disorders 13, 69-76.

Ogden, J. \& Wardle, J. (1990), Cognitive restraint and sensitivity to cues for hunger and satiety. Physiology and Behavior 47, 477-481.

Pangborn, R. M., Bos, K. E. O. \& Stern, J. S. (1985). Dietary fat intake and taste responses to fat in milk by under-, normal, and overweight women. Appetite 6, 25-40.

Polivy, J. (1976). Perception of calories and regulation of intake in restrained and unrestrained subjects. Addictive Behaviors 1, 237-243.

Polivy, J., Herman, C. P., Younger, J. C. \& Erskine, B. (1979). Effects of a model on eating behavior: The induction of a restrained eating style. Journal of Personality 47, 100-114.

Poppitt, S. D. (1995). Energy density of diets and obesity. International Journal of Obesity 19, Suppl. 5 , S20-S26.

Prentice, A. (1995). Are all calories equal? In Weight Control: The Current Perspective, pp. 8-33 [R. Cottrell, editor]. London: Chapman \& Hall.

Ravussin, E. \& Swinburn, B. A. (1992). Pathophysiology of obesity. Lancet 340, $404-408$.

Ries, W. (1973). Feeding behaviour in obesity. Proceedings of the Nutrition Society 32, 187-193.

Rodin, J. (1980). Changes in perceptual responsiveness following jejunoileostomy: Their potential role in reducing food intake. American Journal of Clinical Nutrition 33, 457-464.

Rodin, J. (1981). Current status of the internal-external hypothesis for obesity: What went wrong? American Psychologist 36, 361-372.

Rodin, J., Moskowitz, H. R. \& Bray, G. A. (1976). Relationship between obesity, weight loss, and taste responsiveness. Physiology and Behavior 17, 591-597.

Rodin, J., Schank, D. \& Striegel-Moore, R. (1989). Psychological features of obesity. Medical Clinics of North America 73, 47-66.

Rodin, J. \& Slochower, J. (1976). Externality in the nonobese: Effects of environmental responsiveness on weight. Journal of Personality and Social Psychology 33, 338-344.

Rogers, P. J. \& Hill, A. J. (1989). Breakdown of dietary restraint following mere exposure to food stimuli: interrelationships between restraint, hunger, salivation, and food intake. Addictive Behaviors 14, 387-397.

Ruderman, A. J., Belzer, L. J. \& Halperin, A. (1985). Restraint, anticipated consumption, and overeating. Journal of Abnormal Psychology 94, 547-555.

Ruxton, C. H. S., Kirk, T. R., Belton, N. R. \& Holmes, M. A. M. (1994). Few differences in daily intake associated with a high intake of snacks in school children. Proceedings of the Nutrition Society 53, 253A.

Schachter, S. (1971). Some extraordinary facts about obese humans and rats. American Psychologist 26, 129-144.

Schachter, S. \& Rodin, J. (1974). Obese Humans and Rats. Washington, DC: Erlbaum/Halsted.

Schutz, Y. (1995). Abnormalities of fuel utilization as predisposing to the development of obesity in humans. Obesity Research 3, Suppl. 2, 173s-178s. 
Simoes, E. J., Byers, T., Coates, R. J., Serdula, M. K., Mokdad, A. H. \& Heath, G. W. (1995). The association between leisure-time physical activity and dietary fat in American adults. American Journal of Public Health 85, 240-244.

Spitzer, L. \& Rodin, J. (1981). Human eating behavior: A critical review of studies in normal weight and overweight individuals. Appetite 2, 293-329.

Stunkard, A. J. \& Messick, S. (1985). The Three-Factor Eating Questionnaire to measure dietary restraint, disinhibition and hunger. Journal of Psychosomatic Research 29, 71-78.

Summerbell, C. (1989). Feeding pattern and body weight in humans. PhD Thesis, CNAA, London.

Thompson, D. A., Moskowitz, H. R. \& Campbell, R. G. (1977). Taste and olfaction in human obesity. Physiology and Behavior 19, 335-337.

Tremblay, A. \& Alméras, N. (1995). Exercise, macronutrient preferences and food intake. International Joumal of Obesity 19, Suppl. 4, S97-S101.

Tuschl, R. J., Platte, P., Laessle, R. G., Stichler, W. \& Pirke, K.-M. (1990). Energy expenditure and everyday eating behavior in healthy young women. American Journal of Clinical Nutrition 52, 81-86.

Van Strein, T., Frijters, J. E. R., Bergers, G. P. A. \& Defares, P. B. (1995). On the relationship between emotional and external eating behavior. Addictive Behaviors 20, 585-594.

Van Strein, T., Frijters, J. E. R., van Stavaren, W. A., Defares, P. B. \& Deurenberg, P. (1986a). The predictive validity of the Dutch Restrained Eating Scale. International Journal of Eating Disorders 5, 747-755.

Van Strein, T., Schippers, G. M. \& Cox, W. M. (1986b). The Dutch Eating Behaviour Questionnaire (DEBQ) for assessment of restrained, emotional, and external eating behaviour. International Journal of Eating Disorders 5, 295-315.

Verboeket-van de Venne, W. P. H. G., Westerterp, K. R. \& Kester, A. D. M. (1993). Effect of the pattern of food intake on human energy metabolism. British Journal of Nutrition 70, 103-115.

Verboeket-van de Venne, W. P. H. G., Westerterp, K. R. \& ten Hoor, F. (1994). Substrate utilization in man: Effects of dietary fat and carbohydrate. Metabolism 43, 152-156.

Wardle, J. (1987). Compulsive eating and dietary restraint. British Journal of Clinical Psychology 26, 47-55.

Warwick, Z. S. \& Schiffman, S. S. (1990). Sensory evaluations of fat-sucrose and fat-salt mixtures: Relationship to age and weight status. Physiology and Behavior 48, 633-636.

Weber, J. M., Klasges, R. C. \& Klesges, L. M. (1988). Dietary restraint and obesity: Their effects on dietary intake. Journal of Behavioral Medicine 11, 185-199.

Westerterp-Plantenga, M. S., van den Heuvel, E., Wouters, L. \& ten Hoor, F. (1992). Diet-induced thermogenesis and cumulative food intake curves as a function of familiarity with food and dietary restraint in humans. Physiology and Behavior 51, 457-465.

Westerterp-Plantenga, M. S., Wouters, L. \& ten Hoor, F. (1991). Restrained eating, obesity, and cumulative food intake curves during four-course meals. Appetite 16, 149-158.

Witherly, S. A., Pangborn, R. M. \& Stern, J. S. (1980). Gustatory responses and eating duration of obese and lean adults. Appetite 1, 53-63. 